“(C) 2019 IEEE. Personal use of this material is permitted. Permission from IEEE must be obtained for all other uses, in any current or future media, including reprinting/republishing this material for advertising or promotional purposes, creating new collective works, for resale or redistribution to servers or lists, or reuse of any copyrighted component of this work in other works." 


\title{
Application of Constrained Energy Minimization (CEM) algorithm to ASTER data for alteration mineral mapping
}

\author{
Amin Beiranvand Pour ${ }^{* 1}$, Tae-Yoon S. Park ${ }^{1}$, Yongcheol Park ${ }^{1}$, Jong Kuk Hong ${ }^{1}$ and Biswajeet Pradhan ${ }^{2,3}$ \\ ${ }^{1}$ Korea Polar Research Institute (KOPRI) \\ Songdomirae-ro, Yeonsu-gu, Incheon 21990, Republic of Korea \\ ${ }^{2}$ Centre for Advanced Modelling and Geospatial Information Systems (CAMGIS), \\ Faculty of Engineering and Information Technology, \\ University of Technology Sydney, 2007 New South Wales, Australia \\ ${ }^{3}$ Department of Energy and Mineral Resources Engineering, \\ Choongmu-gwan, Sejong University, 209 Neungdong-ro Gwangjin-gu, \\ Seoul 05006, Republic of Korea
}

\begin{abstract}
Several regions remain poorly studied in terms of geological mapping and mineral exploration in inaccessible regions especially in the Arctic and Antarctica due to harsh conditions and logistical difficulties. Application of specialized image processing techniques is capable of revealing the hidden linearly mixed spectral sources in multispectral and hyperspectral satellite images. In this study, the application of Constrained Energy Minimization (CEM) algorithm was evaluated for the Advanced Spaceborne Thermal Emission and Reflection Radiometer (ASTER) remote sensing data for geological mapping in Morozumi Range and Helliwell Hills areas, Northern Victoria Land (NVL), Antarctica. The results of this investigation demonstrate the capability of the algorithms in distinguishing subpixel targets in the multispectral satellite data. The application of the method for identifying poorly exposed geologic materials and subpixel exposures of alteration minerals has invaluable implications for geological mapping and mineral exploration in inaccessible regions.
\end{abstract}

Keywords-CEM; ASTER; SWIR bands; alteration minerals; Antarctic environments.

\section{INTRODUCTION}

Geological investigations in the Arctic and Antarctica confront many difficulties due to their remoteness and extreme environmental conditions. Largely, due to harsh conditions and logistical difficulties, many areas remain poorly studied in terms of geological mapping and mineral exploration point of view. Recently, few studies emphasized the application of remote sensing satellite imagery for geological mapping in the Arctic and Antarctic environments [1,2].

In particular, remote sensing satellite imagery has high potential to provide a solution to overcome the difficulties and limitations associated with geological field mapping and mineral exploration in the inaccessible region such Antarctic environments. The Advanced Spaceborne Thermal Emission and Reflection Radiometer (ASTER) is a high spatial, spectral and radiometric resolution multispectral remote sensing sensor. It consists of three separate instrument subsystems, which provide observation in three different spectral regions of the electromagnetic spectrum, including visible and nearinfrared (VNIR), shortwave infrared (SWIR) and thermal infrared (TIR). The VNIR subsystem has three recording channels between 0.52 and $0.86 \mu \mathrm{m}$ with a spatial resolution of up to $15 \mathrm{~m}$. The SWIR subsystem has six recording channels from 1.6 to $2.43 \mu \mathrm{m}$, at a spatial resolution of $30 \mathrm{~m}$, while the TIR subsystem has five recording channels, covering the 8.125 to $11.65 \mu \mathrm{m}$ wavelength region with a spatial resolution of $90 \mathrm{~m} \mathrm{[3]}$. There is plenty of research that used ASTER data in mineral exploration and lithological mapping during last decade due to spectral characteristics of the unique integral bands of ASTER in VNIR, SWIR and TIR parts of the electromagnetic spectrum and the possibility of applying several image processing algorithms $[4,5,6]$.

The highest percentage of exposed rocks and soils in Antarctica occurs along the Transantarctic Mountains (TAM) from the Pacific to the Atlantic side of the continent, especially in Northern Victoria Land (NVL) (Fig. 1), where over $5 \%$ of the emerged land is ice-free. Rocks now exposed in NVL were part of the over $4000 \mathrm{~km}$ long paleo-Pacific margin of East Gondwana during the Paleozoic time [7].

In this investigation, the application of Constrained Energy Minimization (CEM) algorithm is evaluated for detailed mapping of exposed lithologies and alteration mineral zones in Morozumi Range and Helliwell Hills regions of NVL using ASTER remote sensing data. The Morozumi Range and Helliwell Hills regions of NVL (Fig. 2) were selected for the present study because their exposed lithological units are located in the remote and inaccessible zone (between Gressitt and Rennick Glaciers of the NVL).

\section{MATERIALS AND METHODS}

\section{A. Geology of the study area}

The Morozumi Range and Helliwell Hills are a group of hills and mountains located between USARP Mountains and 
Rennick Glacier in the WT (Figs. 1 and 2). Their extension is roughly NW-SE parallel to the orientation of the Rennick Glacier. The Morozumi Range igneous complex is composed of various intrusive rocks of Granite Harbour Intrusive (GHI) and hosts by the Morozumi phylites (Fig. 2). The metasedimentary units are unconformably overlain by the Permian sandstones of the Beacon Supergroup. The Helliwell Hills is $35 \mathrm{~km}$ long and $15 \mathrm{~km}$ wide, with average topographic relief of $400 \mathrm{~m}$. The hills are characterized by the unconformity exposed along the long axis of the area. Granite Harbour Intrusive (GHI) and Willson metamorphic rocks occur in the west of the unconformity and Beacon Supergroup and Ferrar Dolerites in the east (Fig. 2). The similar unconformity can be traced in the central part of the Morozumi Range along its length [8].

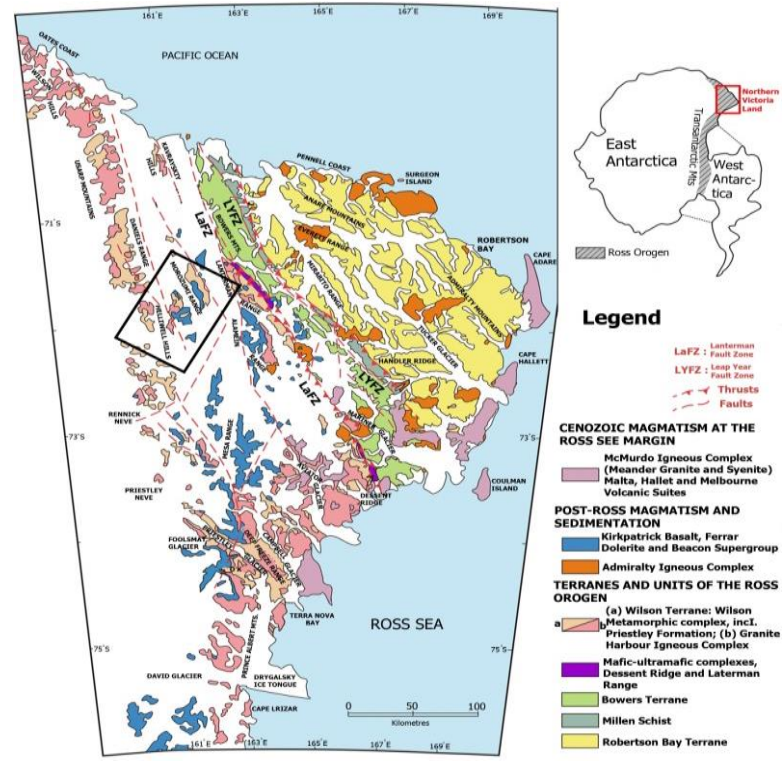

Fig.1. Geological and tectonic sketch map of Northern Victoria Land (NVL).

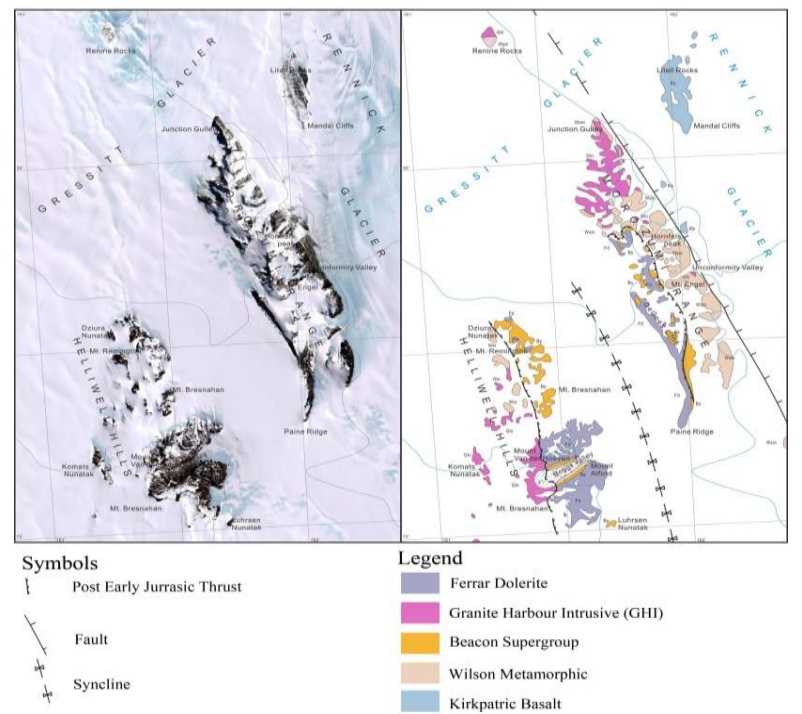

Fig.2. Google Earth image and geology map of the Morozumi Range and Helliwell Hills regions.

\section{B. Remote sensing data}

An ASTER level 1T scene (Path/Row 068/111) covering the Morozumi Range and Helliwell Hills areas was obtained from U.S. Geological EROS (http://glovis.usgs.gov/). It was acquired on January 2, 2005. Sun elevation and azimuth were recorded as 34.665 and 53.756, respectively. Scene cloud cover is $4 \%$ for the ASTER image used in this study. The ASTER images used in this study were pre-georeferenced to UTM zone 57 South projection using the WGS-84 datum.

\section{Data processing}

Preprocessing of ASTER data was also required before analysis. Crosstalk correction was performed on the ASTER datasets used in this study. FLAASH atmospheric correction algorithm was applied on SWIR subsystems of the ASTER datasets. To minimize the reflectance effects of snow, ice and cloud areas from ASTER scene a masking procedure was used to restrict image processing algorithms to just regions of exposed rock. The CEM is a target signature-constrained approach, which constrains the desired target signature with a specific gain while minimizing effects caused by other unknown signatures [9].

The CEM approach utilizes a finite impulse response (FIR) filter to linearly constrain a desired object with minimal interference from other unknown signal sources (Harsanyi 1993). Let $\mathbf{d}_{\mathrm{CEM}}$ be the spectral signature of an object of interest. The goal is to design a FIR linear filter specified by an $n$-dimensional vector $\mathbf{w}=\left(w_{1}, w_{2}, \mathrm{~L}, w_{n}\right)^{T}$ that passes the desired signature $\mathbf{d}_{\text {CEM }}$ by constraining its direction while minimizing its output energy that is caused by signal source vectors with directions other than the constrained direction. Specifically, let $y_{i}$ denote the output of the designed FIR filter resulting from the $i$-th image pixel $\mathbf{r}_{i}$. Then $y_{i}$ can be expressed by

$$
y i=\sum_{l=1}^{n} \quad \mathbf{w}_{l} \mathbf{r}_{i l=\mathbf{w}^{T}} \mathbf{r}_{i=} \mathbf{r}_{i}^{T} \mathbf{w}
$$

the optimal weight is given from [10] as

$$
\mathrm{w}^{*}=\frac{R_{n x n}^{-1} d_{C E M}}{d_{C E M}^{T} R_{n x n}^{-1} d_{C E M}}
$$

where $\mathbf{R}_{n x n}$ is the auto-correlation sample matrix of the multispectral image, and the CEM filter as a detector $\delta_{C E M}(\mathbf{r})$ on an image pixel vector $\mathbf{r}$ is given by 


$$
\delta_{C E M}(\mathbf{r})=\left(\mathbf{W}^{*}\right)^{T} \mathbf{r}=\left(\frac{R_{n \times n}^{-1} d_{C E M}}{d_{C E M}^{T} R_{n \times n}^{-1} d_{C E M}}\right){ }^{T} \mathbf{r}=\left(\frac{d_{C E M}^{T} R_{n \times n}^{-1} r}{d_{C E M}^{T} R_{n \times n}^{-1} d_{C E M}}\right)
$$

Particularly, the value of $\delta_{\mathrm{CEM}}(\mathbf{r})$ resulting from Eq. (4) represents the estimated amount of the abundance fraction of the object signature $\mathbf{d}_{\text {CEM }}$ contained in the image pixel $\mathbf{r}$. Accordingly, the CEM implements a partial unmixing of spectra to estimate the abundance of user-defined endmember materials from a set of reference spectra (either image or laboratory spectra) [10].

In this analysis, the reference spectra of selected end-member minerals for performing CEM were extracted from the USGS spectral library version 7.0 [11]. Hematite, goethite, jarosite, alunite, kaolinite, muscovite, epidote, chlorite, calcite, quartz, opal and chalcedony were selected. To apply the CEM to VNIR+SWIR ASTER data, new covariance statistics were computed. Subspace background was implemented to remove anomalous pixels before calculating background statistics. The fraction of the background in the anomalous image was adjusted by the threshold of 0.750 for the entire image for calculating the subspace background statistics. Covariance matrix method was selected for the calculation. The results of CEM appear as a series of grayscale images, one for each selected endmember. Rule image classifier tool was used for post classification of the resultant images. They were classified by maximum value option, and 0.050 was selected as an appropriate threshold value for all resultant rule images.

\section{RESULTS AND DISCUSSION}

Two spatial subsets of ASTER scene covering the Morozumi Range and Helliwell Hills areas were selected for implementation of the CEM algorithm herein. Fractional abundance of the target endmember minerals was detected using CEM algorithm for the selected zones, separately. Twelve fraction images resulted from this analysis for the selected zones, appear as a series of grayscale rule images, one for each selected endmember. Bright pixels (high Digital Number (DN) value) in each grayscale image show a high fractional abundance of the target mineral. The value in the rule image represents the subpixel abundance of the target mineral in each pixel.

Figure 3 shows CEM classification image map for the Morozumi Range. Some target endmember minerals such as chlorite/hematite, goethite/jarosite/calcite and kaolinite/muscovite are spectrally governed the Morozumi Range and their corresponding fraction images map out the minerals' distribution. Other minerals such as alunite, epidote, opal, chalcedony and quartz have less contribution in total mixed spectral features of the study zone (Fig. 3).

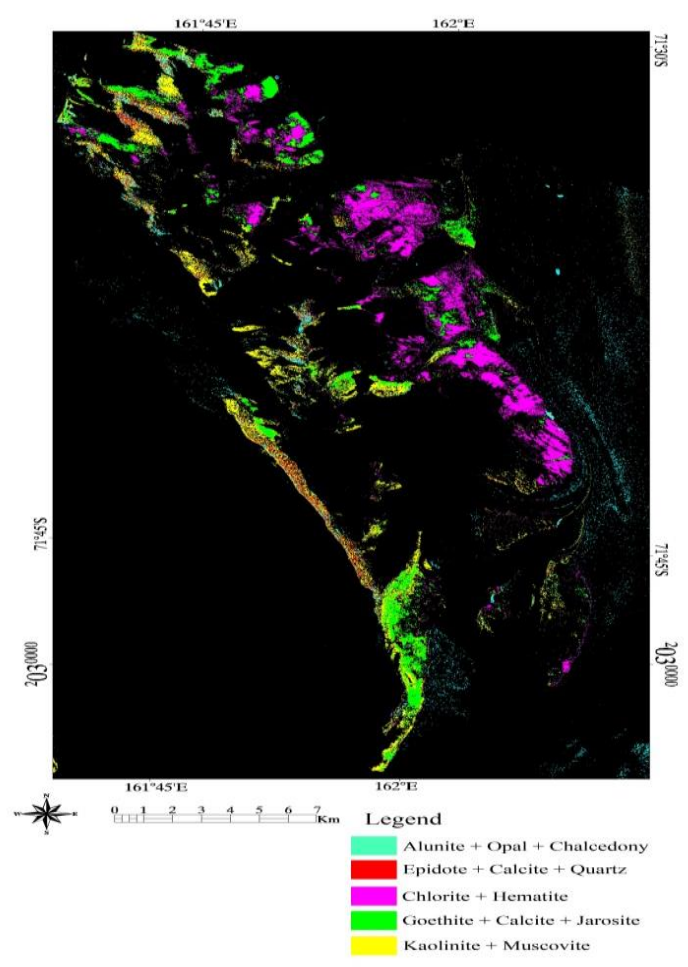

Fig. 3. CEM classification image map for the Morozumi Range spatial subset zone.

CEM classification image map for the Helliwell Hills region is shown in Figure 4. Analysis of the results indicates that goethite, chlorite, hematite and epidote are most dominated mineral assemblages in this zone. Jarosite, muscovite, kaolinite and alunite are shown the second fractional abundance of mineral assemblages, while calcite, opal, chalcedony and quartz have very low surface distribution in the Helliwell Hills region.

Goethite, jarosite, hematite, chlorite and epidote show the high surface distribution in this zone, which are mostly associated with exposures of the Ferrar Dolerite and Beacon Supergroup (see Figs 2 and 4). However, goethite and jarosite are mostly detected with the Ferrar Dolerite due to the fact that they are alteration products of primary mafic minerals within this lithology. Chlorite, hematite, epidote and alunite are associated with the Beacon Supergroup and Wilson metamorphic. Small exposures of the Granite Harbour Intrusive (GHI) in the southwestern part of the selected zone show a fractional abundance of hematite, chlorite, goethite, jarosite, epidote, calcite and quartz, respectively (see Figs 2 and 4). These mineral assemblages are present as the alteration products of primary feldspars and mafic minerals within these rocks, which are consistent with the lithologic variation from granite to granodiorite. Rock samples were collected from altered and weathered lithological units for laboratory analysis. The X-ray diffraction (XRD) analyses were implemented on the bulk powder of the samples using a 
SmartLab® X-ray Diffractometer model for the identification of fine-grained minerals.

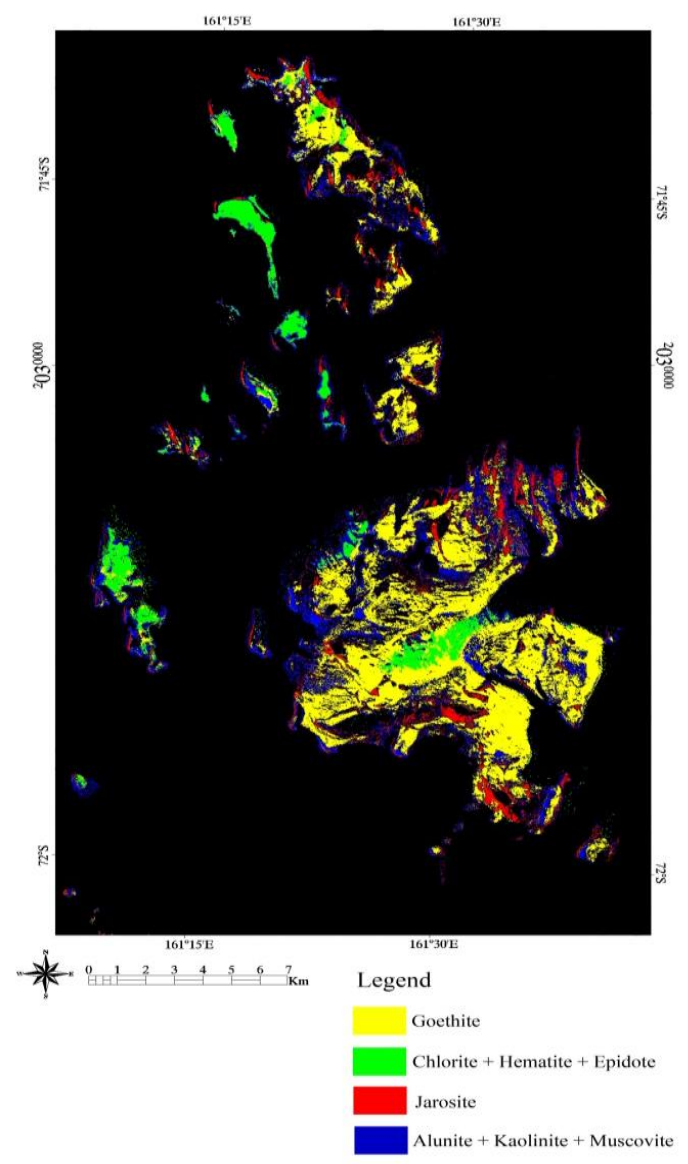

Fig. 4. CEM classification image map for the Helliwell Hills spatial subset zone.

The XRD analysis indicated that hematite, jarosite, goethite, chlorite, epidote, montmorillonite, kaolinite, muscovite, illite and quartz were the major minerals in the collected rock samples from the Ferrar Dolerite and Wilson metamorphic. The mineral assemblages detected in the collected rock samples from the Granite Harbour Intrusive (GHI) and Beacon Supergroup using XRD analysis consisted mainly of kaolinite, montmorillonite, muscovite, illite, calcite, chlorite, epidote, hematite and quartz.

\section{CONCLUSIONS}

The application of Constrained Energy Minimization (CEM) algorithm was evaluated for detailed mapping of exposed lithologies and alteration mineral zones in Morozumi Range and Helliwell Hills region of NVL using ASTER remote sensing data. Fraction images of endmember target minerals such as hematite, goethite, jarosite, alunite, kaolinite, muscovite, epidote, chlorite, calcite, quartz, opal and chalcedony were produced using CEM algorithm for two spatial subsets of ASTER scene covering the Morozumi
Range and Helliwell Hills areas. CEM classification image maps indicated that chlorite/hematite, goethite/jarosite/calcite and kaolinite/muscovite are governed in the Morozumi Range and goethite, chlorite, hematite and epidote are most dominated mineral assemblages in the Helliwell Hills area. The results of the investigation demonstrate that these algorithms hold great potential for geological mapping applications and should be of special interest for Polar Earth scientists who might have very limited ground truth, for geologic mapping in areas with significant vegetative cover as well as for mineral exploration by enabling the detection of subpixel exposures of minerals indicative of hydrothermal alteration zones.

\section{Acknowledgment}

We are thankful to Korea Polar Research Institute (KOPRI) for providing the facilities for this investigation. This study was conducted as a part of KOPRI grant PE17050 and PE17160.

\section{References}

[1] Pour, A.B., Hashim, M., Park, Y., Hong, J.K. Mapping alteration mineral zones and lithological units in Antarctic regions using spectral bands of ASTER remote sensing data. Geocarto International, 2017a, doi.org/10.1080/10106049.2017.1347207.

[2] Pour, A.B., Hashim, M., Hong, J.K., Park, Y. Lithological and alteration mineral mapping in poorly exposed lithologies using Landsat-8 and ASTER satellite data: north-eastern Graham Land, Antarctic Peninsula. Ore Geology Reviews, 2017b, doi.org/10.1016/j.oregeorev.2017.07.018

[3] Yamaguchi Y.I., Fujisada, H., Kahle, A.B., Tsu, H., Kato, M., Watanabe, H., Sato, I. and Kudoh, M. ASTER instrument performance, operation status, and application to Earth sciences. IEEE Transactions of Geosciences and Remote Sensing, 2001, p. 1215-1216.

[4] Amer, R., El Mezayen, A., Hasanein, M. ASTER spectral analysis for alteration minerals associated with gold mineralization. Ore Geology Reviews, 2016, 75, 239-251

[5] Mars, J. C. and Rowan, L.C. ASTER spectral analysis and lithologic mapping of the Khanneshin carbonate volcano, Afghanistan. Geosphere, 2011, 7, 276-289.

[6] Pour, B.A. and Hashim, M. The application of ASTER remote sensing data to porphyry copper and epithermal gold deposits. Ore Geology Reviews. 2012, 44, 1-9.

[7] Veevers, J.J. Edge tectonics (Trench rollback, terrane export) of Gondwanaland-Pangea synchronized by supercontinental heat. Gondwana Research. 2005, 8, 449-456.

[8] Woo, J. Excursion information map of Northern Victoria Land, Antarctica, with information of the basecamp at Helliwell Hills", Korea Polar Research Institute. 2016, pp 3-6.

[9] Chang, C.I., Heinz, D.C. Constrained subpixel target detection for remotely sensed imagery. IEEE Transactions on Geoscience and Remote sensing. 2000, 38 (3), 1144-1159.

[10] Harsanyi, J. C. Detection and classification of subpixel spectral signatures in hyperspectral image sequences, $\mathrm{Ph}$. D. thesis, University of Maryland. 1993.

[11] Kokaly, R.F., Clark, R.N., Swayze, G.A., Livo, K.E., Hoefen, T.M., Pearson, N.C., Wise, R.A., Benzel, W.M., Lowers, H.A., Driscoll, R.L., and Klein, A.J. "USGS Spectral Library Version 7": U.S. Geological Survey Data Series 1035, 2017. 61 p., https://doi.org/10.3133/ds1035. 